\title{
DESIGN OF MULTI SPINDLE DRILLING MACHINE
}

\author{
Pravin A. Desai \\ Lecturer, Mechanical Engg. Department, \\ Rajarambapu Institute of Technology, Rajramanagar, Maharashtra, India \\ Vishal V. Jadhav \\ Lecturer, Mechanical Engg. Department, \\ Rajarambapu Institute of Technology, Rajramanagar, Maharashtra, India
}

\begin{abstract}
The growth of Indian manufacturing sector depends largely on its productivity \& quality. Productivity depends upon many factors, one of the major factors being manufacturing efficiency with which the operation lactivities are carried out in the organization. Productivity can be improved by reducing the total machining time, combining the operations etc. In case of mass production where variety of jobs is less and quantity to be produced is huge, it is very essential to produce the job at a faster rate. This is not possible if we carry out the production by using general purpose machines. The best way to improve the production rate (productivity) along with quality is by use of special purpose machine. Usefulness and performance of the existing radial drilling machine will be increased by designing of multispindle drilling head attachment. This paper deals with design and development of multispindle drilling head for cycle time optimization of the component. The report presented here gives detailed overview of making of the Special purpose machine. This report touches to numerous aspects of engineering, which has been covered in the curriculum of $U G$ and $P G$ programs of Mechanical engineering. The report is compiled with a simple and easy to follow approach for building up of a machine. It consist of design of gear, shaft, bearing, etc.
\end{abstract}

Key words: multispindle, Drilling Machine, Mechanical engineering.

Cite this Article: Pravin A. Desai and Vishal V. Jadhav, Design of Multi Spindle Drilling Machine. International Journal of Design and Manufacturing Technology 8(2), 2017, pp. 01-22.

https://iaeme.com/Home/issue/IJDMT?Volume $=8 \&$ Issue $=2$

\section{INTRODUCTION}

An effort is taken to design and develop a Special purpose machine for Multi spindle drilling of cylinder head. The machine is meant for drilling 12 holes at bottom faces of the cylinder head, and the provision is made to accommodate two jobs in single setup. The component fits 
in the assembly of diesel engines manufactured by John Deere Pune. The report presented here gives detailed overview of making of the Special purpose machine from scratch and its installation. The report touches to numerous aspects of engineering, which has been covered in the curriculum of UG programs of Mechanical engineering. The report is compiled with a simple and easy to follow approach for building up of a machine. The Special purpose machine assembly and subassemblies are elaborated using photographs and video clips whenever required during the process. The machine consists of fifty plus components along with its process charts. Report covers detailed design and manufacturing scheme of selected critical components. The testing of assembly consists of numerous mechanisms, hydraulic power pack and actuators, a programmable logic controller circuit for auto control of machining cycle. Total cost of production is been calculated as per the available rates of labor and materials of standard and bought out items. The report is a complete reference manual for design and manufacturing of the machine. We have also given my suggestions to future development of machine and some findings which may be helpful for the customer using the set-up. Reader's views, observations, constructive criticism and suggestions are welcome.

\section{COMPONENT DESCRIPTIONS}
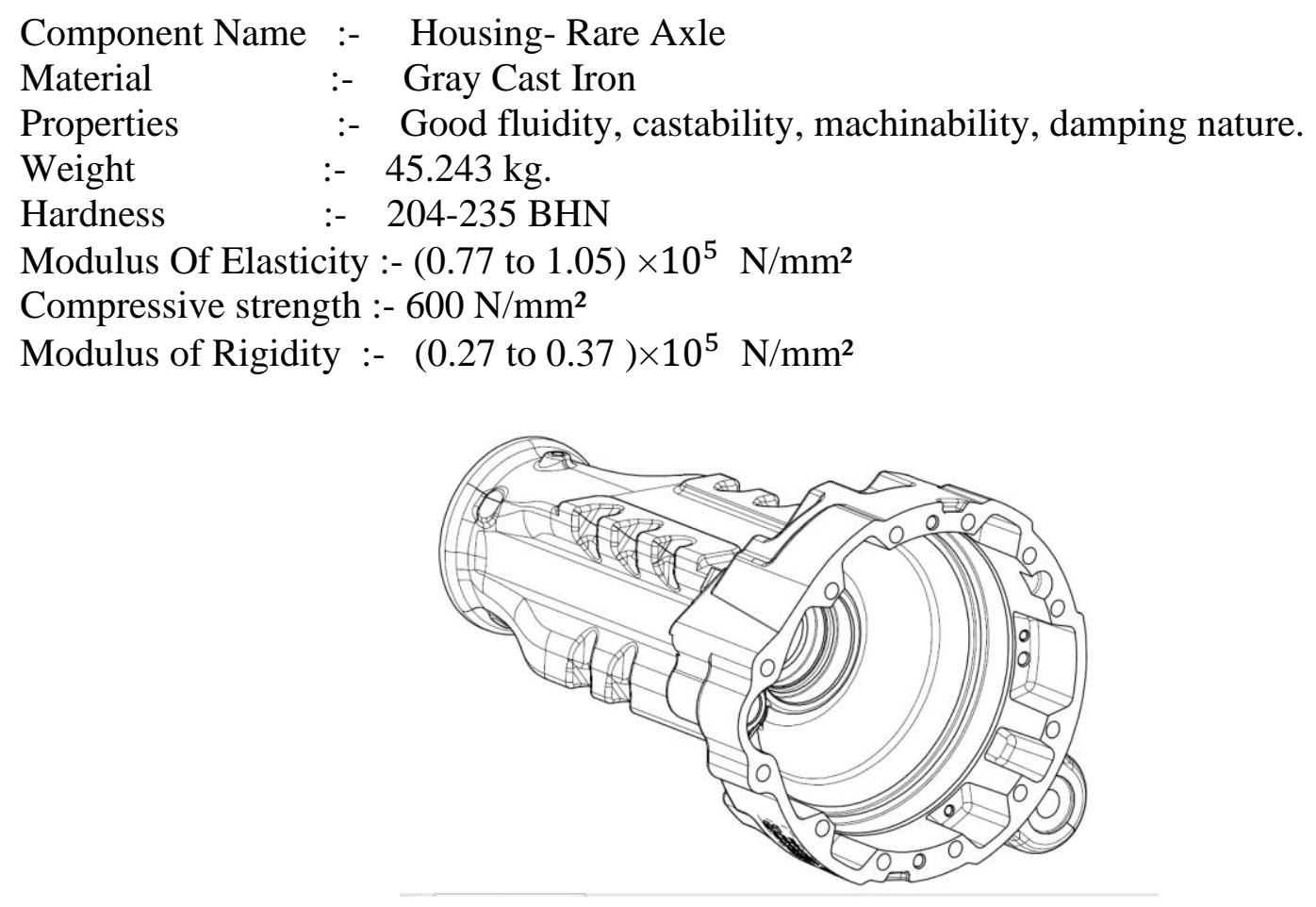

Figure 1 Design of housing

\section{Need For New SPM?}

There is vast demand for housing and Ghatagepatil Industries ltd. is finding it difficult to cope up with the required productivity. Thus in order to fulfill the needs of the customer's new machines is to be employed.

\section{Features Required in New Machine}

The rate of production of existing machine is too low and they find the handling time more. So they need newer machine with automated clamping which would reduce time. Also job loading and unloading should be easy. Since the weight of the job is more, crane is used for 
loading the job on machine. The machine should be designed taking into consideration the loading and unloading feature of job.

\section{PROPOSED METHOD}

\section{Multi Spindle Drilling}

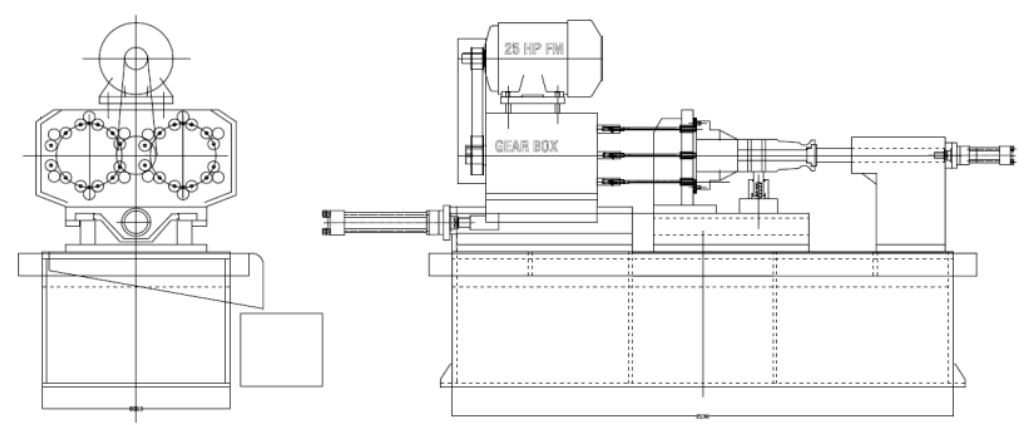

Figure 2 Alternative I for drilling machine

In this method the component is located on horizontal face and the drilling is carried out horizontally.

Resting surface

Casting surface is used for resting

\section{Location}

Bored hole is used in which locater is placed

\section{Clamping}

Hydraulic clamping

\section{Advantages}

- Two jobs can be mounted

- Ease of loading

\section{Disadvantages}

- Length of drilling is $165 \mathrm{~mm}$ so there are chances of ovality in drilling.

- Casting surface is used for resting. And there may be variation in size of casting.

- Require much floor space.

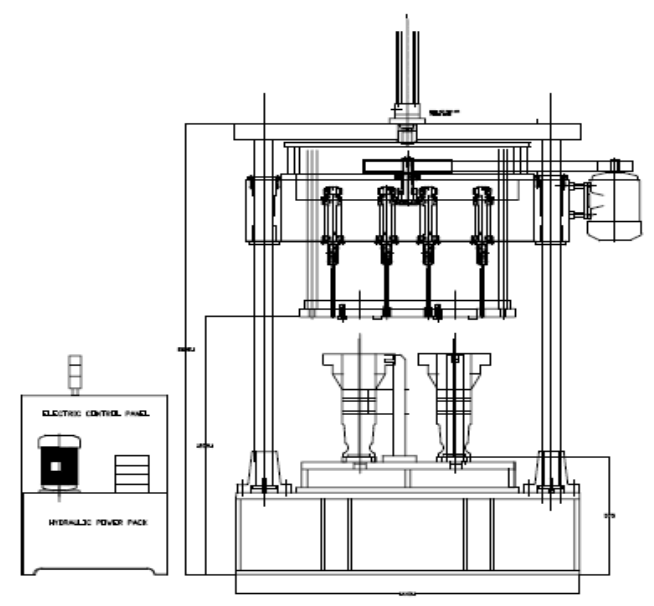

Figure 3 Alternative II for drilling machine 
Job is located vertically on the machined face and the drilling is allowed to carry out in downward direction.

\section{Resting surface}

Machined face is used for resting

\section{Location}

Bored hole is used in which locater is placed

\section{Clamping}

Hydraulic clamping

Advantages

- Two jobs can be mounted

- Since drilling is in the direction of gravity deflection of drill is minimum

- Floor space required is low

\section{Disadvantages}

- Since the job has to be loaded with the help of crane it is difficult to load the job

- Wood pecking system is required for the ease of chip disposal
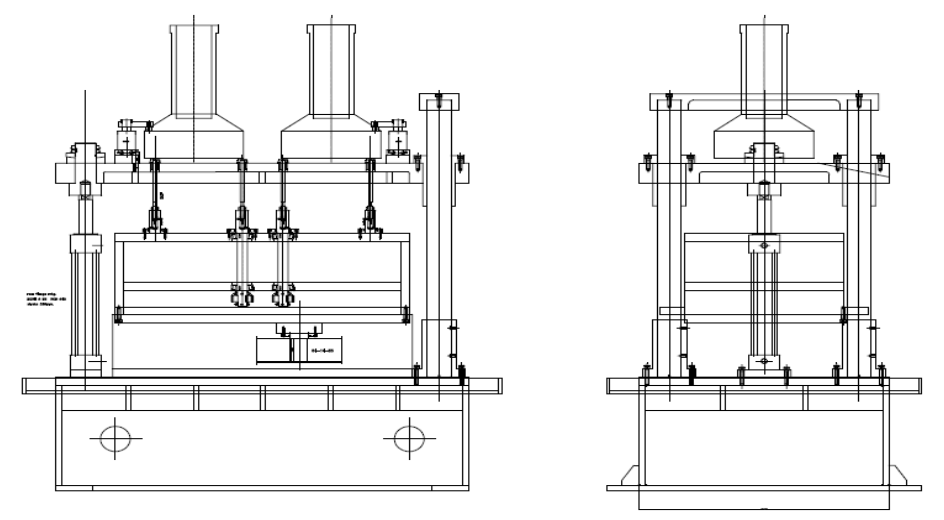

Figure 4 Alternative III for drilling machine

In this method drilling is done in vertically upward direction allowing the chips to fall downwards. Job is rested on the machined face and the dowel holes are used for locating the jobs.

\section{Resting surface}

Machined face is used for resting

\section{Location}

Dowel holes are used in which locater is placed

Clamping

Hydraulic clamping

Advantages

- Two jobs can be mounted

- Crane can be easily operated for job loading

- Wood pecking is not required since the chips will fall downwards

- Low floor space is required

\section{Disadvantages}

- Since the drilling is done against gravity, the taper may found in drilled holes 
- Since the chips fall downward on spindle, chips should be disposed quickly

- Seals are required to protect the entry of chips within spindle bore

\section{FORCE AND POWER CALCULATIONS}

\section{Cutting Parameters}

\section{For cutting speed :-}

From CMTI, Page no .656, table 277 (for drilling)

Component - Grey Cast Iron.

Cutting speed range: $20 \mathrm{~m} / \mathrm{min}$ to $23 \mathrm{~m} / \mathrm{min}$.

As we are not providing cooling fluid, therefore the cutting speed is decreased.

Also, for multispindle drilling is taken less or mentioned in table.

So cutting speed is,

$$
\mathrm{v}=18 \mathrm{~m} / \mathrm{min} \text {. }
$$

For rpm of spindle :

We know, $\quad v=\frac{\pi * d * n}{1000}$

$$
\begin{aligned}
\mathrm{N} & =\frac{1000 * \mathrm{v}}{\pi * \mathrm{~d}} \\
& =\frac{1000 * 18}{\pi * 13.5} \\
\ldots .(\mathrm{d} & =13.5 \mathrm{~mm}) \\
\mathrm{N} & =427 \mathrm{~mm}
\end{aligned}
$$

\section{Feed (for drilling)}

From CMIT page no .656 and table no.278,

For hole diameter of 13.5, Feed is

$$
\mathrm{S}=.15 \mathrm{~mm} / \mathrm{rev} \text {. }
$$

Material factor $(\mathrm{k})$ :

From table no. 272, .CMTI,

Material factor,

$$
\begin{gathered}
\mathrm{K}=1.5 \text { for } \quad 198 \mathrm{HB} \\
=2.03 \text { for } 224 \mathrm{HB}
\end{gathered}
$$

\section{Power at the Spindle}

It is given by,

$\mathrm{P}=1.25 d^{2} \mathrm{kn}(0.056+1.55) / 10^{5}$

$\mathrm{P}=\frac{1.25 *(13.5)^{2} * 1.5 * 427(0.056+1.5 * 0.15)}{10^{5}}$

$\mathrm{P}=0.410018 \mathrm{kw}$

$\mathrm{P}=410.018 \mathrm{w}$

This is the power at one spindle.

For 24 spindles,

Total power $=\mathrm{p} * 24$

$=410.018 * 24$

$=9840.43 \mathrm{kw}$ 
Total Power $=9.840 \mathrm{w}$

$p_{t}=9.840 \mathrm{kw}$

Efficiency of transmission is considered as $90 \%$.

$n_{m}=90 \%$

Power at motor is given by,

$$
\begin{gathered}
p_{n}=\left(p_{t}\right) / \mathrm{n} \\
=(9.840) /(0.9) \\
p_{n}=10.933 \mathrm{kw}
\end{gathered}
$$

This is the power of motor.

We know,

$1 \mathrm{HP}=746 \mathrm{w}=0.746 \mathrm{kw}$.

Power at motor is

$p_{m}=(10.933) /(0.746)$

$p_{m}=14.655 \mathrm{HP}$

$=15 \mathrm{HP}$

This value is obtained from calculations.

We can use 15 HP motor. But in practice any rise in required power more than 15 HP motor is not able to fulfill and machine may stop.

To ensure continuous running of machine, we will use next standard motor.

We select, $20 \mathrm{HP}$

$$
\begin{aligned}
& p_{m}=20 \mathrm{HP} \\
& p_{m}=14.92 \mathrm{kw}
\end{aligned}
$$

\section{Torque at Spindle}

Torque for 1 spindle is given by,

$$
\begin{array}{rl} 
& T_{s}=975 *\left(p_{t} / \mathrm{n}\right) \\
=975 & *(9.84 / 427) \\
& T_{s}=22.468 \mathrm{kgf.m} \\
(\text { As }, 1 \mathrm{kgf.m}=9.81 \mathrm{Nm}) \\
T_{s}=22.468 * 9.81 \mathrm{Nm} \\
T_{S}=220.4148 \mathrm{Nm} \\
T_{s}=220.4148 * 10^{3} \mathrm{Nmm}
\end{array}
$$

This is torque at one speed.

Torque on 24 spindles is,

$\mathrm{T}=T_{S} * 24$

$$
\begin{aligned}
& \mathrm{T}=220.4148 * 10^{3} * 24 \\
& \mathrm{~T}=5289.956 * 10^{3} \mathrm{Nmm}
\end{aligned}
$$

\section{Thrust on Spindle}

Thrust on 1 spindle is given by,

$$
\begin{aligned}
& T_{h 1}=1.16 \mathrm{kd}(100 * s)^{0.84} \\
& T_{h 1}=1.16 * 1.5 * 13.5 *(100 * 0.15)^{0.84} \\
& T_{h 1}=228.454 \mathrm{kgf}
\end{aligned}
$$




$$
\begin{aligned}
& T_{h 1}=228.454 * 9.81 \mathrm{~N} \\
& T_{h 1}=2241.138 \mathrm{~N}
\end{aligned}
$$

Now,

thrust on 24 spindles will be,

$$
\begin{aligned}
& T_{h}=T_{h 1} * 24 \\
& =2241.138 * 24
\end{aligned}
$$

$=53787.32 \mathrm{~N}$

\section{Time for Drilling}

It is given by,

$$
T_{d}=\mathrm{L} / \mathrm{S} * \mathrm{~N}
$$

Here $\mathrm{L}=$ length of drill

$$
\begin{aligned}
\mathrm{S}=\text { feed, } \mathrm{N}=\mathrm{rpm} \\
T_{d}=\frac{(160+10)}{(0.15 * 427)} \\
T_{d}=2.654 \mathrm{~min} \\
T_{d}=159.25 \mathrm{sec} \\
T_{d}=160 \mathrm{sec}
\end{aligned}
$$

\section{SELECTION OF TIMING BELT PULLEY}

\section{Drive Ratio}

D.R $=\frac{\text { Speed of Faster Shaft }}{\text { Speed of Lower Shaft }}$

D. $R=\frac{1000}{430}$

$$
=2.34
$$

\section{Calculation of Design Power}

This can be obtained by multiplying the motor power (p) by application, $f_{1}, f_{2}, f_{3}, f_{4}$ Design power is given by,

$$
P_{d}=\mathrm{P}\left(f_{1}+f_{3}-f_{4}\right) * f_{2}
$$

Where,

$f_{1}$ - Application factor/Service factor

This relates the type of driver and driven equipment for the daily usage.

$f_{2}$ - Application factor

This relates to the speed increasing drives. (refer table no.2)

$f_{3}$ - Application factor

If idler is used then add 0.2

$f_{4}$ - Application factor

If machinery only used intermittently or seasonally deduct 0.2 from service factor.

In our case, equation (1) becomes,

$$
\begin{aligned}
& P_{d}=\mathrm{P} * f_{1} \\
& =15 * 1.7 \\
& =25.5 \mathrm{kw}
\end{aligned}
$$




\section{Selection of Belt Pulley}

Applying the calculated design power and speed of smallest pulley to the "Belt selection graph for metric series Belt" and suitable pitch is selected.

Pitch = 14mm (14 M - designation)

Both metric (HTD) and classical belt drives are available for selection. Generally HTD belts provides a more compact, quieter drive and preferred for new application. So, HTD belts are selected.

\section{Pulley Selection}

For economic and availability reasons it is preferable to use pulleys of max 80 teeth and to minimise belt fatigue a minimum of 20 teeth is preferable.

Generally, 28 teeth, $14 \mathrm{M}$ pitch is standard one and this is used for smaller pulley.

Referring to standard drive ratios - table 3

We selected the no of teeth on large pulley.

For , D.R. = 2.3,

Teeth on larger pulley $=64$.

Thus,

Smaller pulley : 28 teeth, $14 \mathrm{~mm}$ pitch.

Larger pulley : 64 teeth, $14 \mathrm{~mm}$ pitch.

i.e. $Z_{1}=28, Z_{2}=64$.

\section{Determination of Belt Length and Centre Distance}

A) Determination of belt length :

For drives with pulley of dissimilar numbers of teeth, we now, calculate number of teeth in belt,

$N_{c}=\frac{2 * A_{0}}{P}+\frac{Z_{1}+Z_{2}}{2}+\frac{2.533 * \mathrm{p} *\left(Z_{2}-Z_{1}\right)^{2}}{100 * A_{0}}$

Where, $A=$ approximately centre distance $(\mathrm{mm})$

$\mathrm{P}=$ Belt pitch

$N_{C}=\frac{2 * 900}{14}+\frac{28+64}{2}+\frac{2.533 * 14 *(64-28)^{2}}{100 * 900}$

$=175.08$

From standard belt length tables, For 175 teeth in belt for $14 \mathrm{M}$ pitch, belt length is selected.

Belt length, $\mathrm{L}=2450 \mathrm{~mm}$

B) Determination of actual shaft centres :

We have,

$\mathrm{A}=\frac{P}{4}\left[N_{A}-\frac{Z_{1}+Z_{2}}{2}+\sqrt{\left(N_{A}-\frac{Z_{1}+Z_{2}}{2}\right)^{2}-\frac{2.027\left(Z_{2}-Z_{1}\right)^{2}}{10}}\right]$

Where,

$N_{A}=175=$ number of teeths in belt.

$\mathrm{A}=$ actual centre distance.

$A=\frac{14}{4}\left[175-\frac{(28+64)}{2}+\sqrt{\left(175-\frac{(28+64)}{2}\right)^{2}-\frac{2.02764-28)^{2}}{10}}\right]$ 


$$
\mathrm{A}=899.42 \mathrm{~mm}
$$

Now,

$P_{s}=P_{d} * f_{5} * f_{6}$

$P_{S}=25.5 * 1 * 1$

$P_{S}=25.5 \mathrm{kw}$

\section{Belt Width Selection}

We have, selection power

Ps $=25.5 \mathrm{kw}$

Also knowing the size of small pulley and relative shaft speed,

Referring table,we get,

$\mathrm{P}_{\mathrm{r}}=13.51 \mathrm{kw}$

Now, belt width factor is given by,

$\mathrm{W}_{\mathrm{f}}=\frac{P s}{P r}=\frac{25.5}{13.51}=1.887$

Thus, belt width factor is 1.887 .

Now from table, $\mathrm{W}_{\mathrm{f}}=2.32$

Belt width $=85 \mathrm{~mm}$

\section{MESHING GEAR PAIR DESIGN}

The motor which is selected on the basis of power require to drive all mechanism and it transmits to driven gear. The motor speed is comparatively more than speed required for drill tools, so it is need to reduce the speed of motor and which is achieved by speed reduction gear box.

There are total 24 numbers of spindles rotating with same speed of $400 \mathrm{rpm}$ with the help of central main gear. Hence we have considered the diameter of 2 gears.

Considering above factors in mind the design expert from industries and design organization select the material of the gear as En36A having $S_{u t}=1200 \mathrm{~N} / \mathrm{mm}^{2}$.

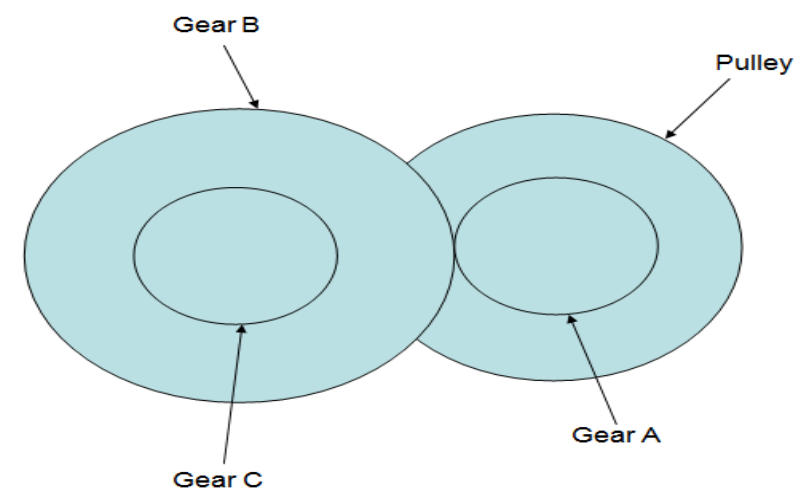

Figure 5 Gear model

As per standard design data and experts from industry selected gear profile is $20^{\circ}$ FDI (full depth involute) profile.

For $20^{\circ}$ pressure angle, minimum number of teeth $Z_{\min }=17$ but due to required speed of spindle and space consideration the diameter of gear should be less than $100 \mathrm{~mm}$.

No. of teeth on gear $\mathrm{A}=Z_{A}=32$. 


\section{Calculation of Module}

\section{for gear pair A and B:}

Power $(\mathrm{kw})=14.92, n_{m}=1000 \mathrm{rpm}, n_{A}=n_{p}=430 \mathrm{rpm}$.

The material selected for gears is En36A. It has tensile strength $s_{u t}=1200 \mathrm{~N} / \mathrm{mm}^{2} . \&$ $\mathrm{BHN}=400$ case.

Now factor of safety $=1.5$

Service factor $=1$

Number of teeth on $A$ are 32 i.e $Z_{A}=32, b=12 \mathrm{~m}, Y=0.364$ for $Z_{A}=32$ teeth.

Pitch line velocity:

Assuming pitch line velocity as $3 \mathrm{~m} / \mathrm{s}$.

Now, velocity factor

$c_{v}=\frac{3}{3+3}=0.5$

Module is given by,

$$
\begin{aligned}
\mathrm{m} & =\left\{\frac{60 * 10^{6}}{\pi}\left(\frac{(k w)(c s)(f s)}{z_{p} \pi n_{p} c_{v} \frac{b s u t}{m} y}\right)\right\}^{\frac{1}{3}} \\
\mathrm{~m} & =\left\{\frac{60 * 10^{6}}{\pi}\left(\frac{(14.92)(1)(1.5)}{32 * 430 * 0.5 * 12 * \frac{1200}{3} * 0.364}\right)\right\}^{\frac{1}{3}} \\
\therefore \mathrm{m} & =3 \mathrm{~mm} .
\end{aligned}
$$

Now,

diameter of gear $=d_{p}=z_{p} . m$

$$
\begin{aligned}
& =3 * 32 \\
& =96 \mathrm{~mm} .
\end{aligned}
$$

Pitch line velocity is,

$\mathrm{v}=\frac{\pi d_{p} n_{p}}{60 * 1000}=\frac{\pi * 96 * 430}{60 * 1000}=2.1614 \mathrm{~m} / \mathrm{s}$

Velocity factor,

$c_{v}=\frac{3}{3+v}=\frac{3}{3+2.1614}=0.58$

Face width, $\mathrm{b}=12 \mathrm{~m}=12 * 3=36 \mathrm{~mm}$.

Addendum $=h_{a}=$ module $=3 \mathrm{~mm}$

Dedendum $=h_{f}=1.25 \mathrm{~m}=1.25 * 3=3.75 \mathrm{~mm}$

Clearance $=\mathrm{c}=0.25 \mathrm{~m}=0.25^{*} 3=0.75 \mathrm{~mm}$.

Tooth thickness $=\mathrm{s}=1.5708 * \mathrm{~m}=1.5708 * 3=4.7124 \mathrm{~mm}$.

For gear A,

$z_{A}=z_{c}=32, N_{p}=430 \mathrm{rpm}=N_{A}$

$$
\text { P.C.D }=m^{*} z_{p}=3 * 32=96 \mathrm{~mm} \text {. }
$$

For gear B,

$$
\begin{aligned}
& z_{b}=\frac{(p . c . d) B}{m}=\frac{150}{3}=50 \\
& N_{B}=\frac{z_{A}}{z_{b}} \times N_{p}=\frac{32}{50}=275.2 \mathrm{rpm}
\end{aligned}
$$


For gear $\mathrm{C}$,

Gear $\mathrm{B}$ and $\mathrm{C}$ are compound gear

$N_{B}=N_{c}=275.2 \mathrm{rpm}$.

P.C.D of gear $\mathrm{C}=96 \mathrm{~mm}$.

$z_{c}=\frac{(p . c . d) C}{m}=\frac{96}{3}=32$

For gear $R_{1}$,

Module, $\mathrm{m}=3 \mathrm{~mm}, z_{1}=22, P . C . D=66 \mathrm{~mm}$

All main gears on RHS and LHS are of same dimension as that of gear $R_{1}$.

For gear $R_{1}$ to $R_{12}$ and $l_{1}$ to $L_{12}$,

Module, $\mathrm{m}=3 \mathrm{~mm}, Z_{p}=22, \mathrm{~N}=400 \mathrm{rpm}$.

For idler gears,

P.C.D $=75 \mathrm{~mm}$ and module, $\mathrm{m}=3 \mathrm{~mm}$.

Number of teeth on idler gear, $Z_{1}{ }^{\prime}=\frac{75}{3}$

$$
Z_{1}^{\prime}=25
$$

Speed of the idler gear

$$
=\frac{Z_{1}}{Z_{1}^{\prime}} * N_{1}=\frac{22}{25} * 400=352 \mathrm{rpm} .
$$

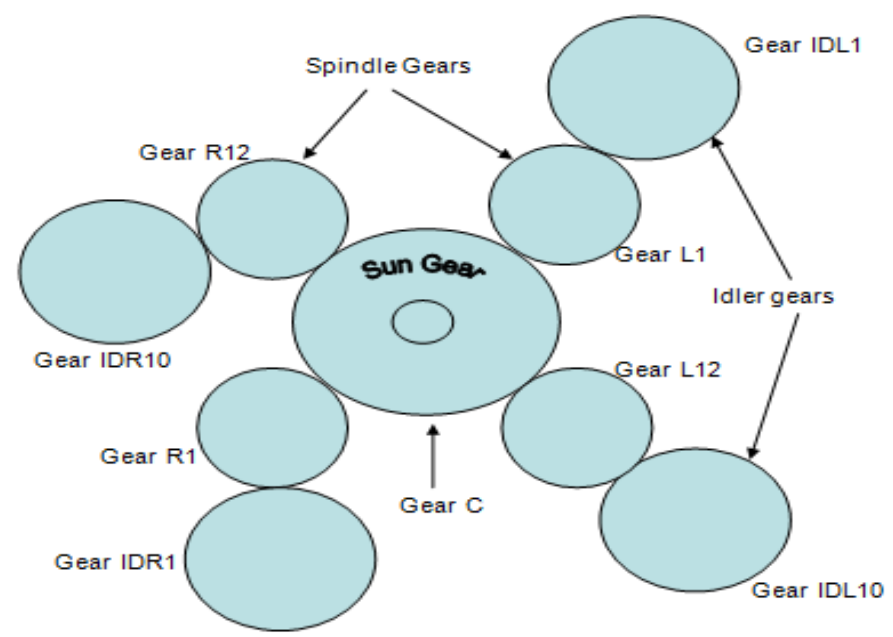

Figure 6 Gear pair design

Gear Pair Design

Pair between gear A and B :

\section{a) Static load on gear:}

Torque transmission $\left(M_{t}\right)$ is given by,

$M_{t}=\frac{60 * 10^{6} * K w}{2 \pi n_{p}}=\frac{60 * 10^{6} * 14.92}{2 \pi * 430}=331.338 * 10^{3} \mathrm{Nmm}$

Now,

tangential load,

$P_{t}=\frac{2 * M_{t}}{d_{A}}=\frac{2 * 331.338 * 10^{6}}{96}=6902.88 \mathrm{~N}$. 


\section{b) Effective tooth load:}

Pitch line velocity,

$\mathrm{V}=\frac{\pi d_{A} * n_{A}}{60 * 1000}=\frac{\pi * 96 * 430}{60 * 1000}=2.1614 \mathrm{~m} / \mathrm{s}$

$C_{v}=\frac{3+v}{3} \ldots \ldots . \quad(\mathrm{v}<10 \mathrm{~m} / \mathrm{s})$

$C_{v}=0.5812$

Effective tooth load,

$P_{\text {eff }}=\frac{C_{s} * P_{t}}{C_{v}}=\frac{1.5 * 6902.8}{0.5812}=13064.6 \mathrm{~N}$

Beam strength,

$S_{b}=m * b * \sigma_{b} * Y$

$S_{b}=3 * 36 * \frac{1200}{3} * 0.364=15724.8 \mathrm{~N}$

To avoid tooth failure due to bending, $S_{b}>P_{\text {eff }}$

$S_{b}=P_{\text {eff }} * f . s$

$f . s=\frac{S_{b}}{P_{\text {eff }}}=\frac{15724.8}{13064.6}=1.2$

Thus, Design is safe.

\section{c) Dynamic load on gear}

In final stage of gear design, when gear dimensions are known error specified and quality is determined. We will select finer grade for the manufacture to reduce the dynamic load because it is essential to get design satisfactory both from standard point of strength and wear. The error depends upon the quantity of gear and method of manufacture.

Dynamic load is calculated by M.F.Spotts equations, it is given by,

$P_{d}=\frac{21 v\left[C_{e b}+P_{t}\right]}{21 v+\sqrt{C_{e b}+P_{t}}}$

Hence error, $\mathrm{e}=$ error in tooth profile.

Gears are having the grade $6, \mathrm{e}=8+0.63(\mathrm{~m}+0.25 \sqrt{D})$

For gear A, $\quad e_{A}=8+0.63(3+0.25 \sqrt{96})=11.43 \mu \mathrm{m}$

For gear $\mathrm{B}, \quad e_{B}=8+0.63(3+0.25 \sqrt{150})=11.82 \mu \mathrm{m}$

$\mathrm{e}=e_{A}+e_{B}=11.43+11.82=23.25 \mu \mathrm{m}$

Value of deformation factor, $\quad \mathrm{C}=1140 \mathrm{~N} / \mathrm{mm}^{2}$

Also, $\quad \mathrm{v}=2.1614 \mathrm{~m} / \mathrm{s}, \mathrm{b}=36 \mathrm{~mm}$ and $P_{t}=6902.88 \mathrm{~N}$

Now,

$P_{d}=\frac{21 * 2.1614 *\left\{1140 * 23.5 * 10^{-3} * 36+6902.88\right\}}{21 * 2.1614+\sqrt{\left(1140 * 23.25 * 10^{-3} * 36\right)+6902.88}}$

$P_{d}=4298.9 \mathrm{~N}$

Now,

$P_{\text {eff }}=\mathrm{G} * P_{t}+P_{d}=1.1 * 6902.88+4298.9=11892.14 \mathrm{~N}$.

$f_{S}=\frac{S_{b}}{\text { eff }}=\frac{15724.8}{11892.14}=1.32$

$\therefore$ Design is safe. 
d) Wear strength is given by,

$s_{w}=d_{A} \mathrm{~b}$ Q k

Where, $\mathrm{Q}=$ ratio factor $=\frac{2 * Z_{B}}{Z_{B}-Z_{A}}=\frac{2 * 50}{50-32}=5.55$

$$
\mathrm{K}=0.16 *\left(\frac{B H N}{100}\right)^{2}
$$

To avoid gear failure due to pitting, $S_{w}>P_{e f f}$

Let, F.s $=2$

$S_{w}=2 * P_{\text {eff }}$

$S_{w}=2 * 11892.14=23784.3 \mathrm{~N}$

From equation (1),

$$
23784.3=96 * 36 * 5.55 * 0.16 *\left(\frac{B H N}{100}\right)^{2}
$$

$\mathrm{BHN}=278 \cong 300$

$\therefore$ Required hardness is $300 \mathrm{BHN}$.

Similarly this procedure is followed for all gear pairs.

\section{DESIGN OF SHAFT}

\section{Design of Idler Shaft}

Selection of material for shaft:

The shaft should have sufficient strength to resist failure due to breakage, provide rigidity and gives more stability.

Considering above factors in mind the design experts from industries and design organization select the material for shaft as SAE8620.

$\mathrm{SAE} 8620 \rightarrow 20 N_{i} 2 C_{r} 1 M_{o} 15$

Composition $\rightarrow 0.20 \% \mathrm{C}, N_{i^{-}} 2 \%, C_{r}-1 \%, M_{o}-0.15 \%$

$$
\begin{gathered}
s_{u t}=800 \mathrm{~N} / \mathrm{mm}^{2} \\
S_{y t}=530 \mathrm{~N} / \mathrm{mm}^{2}
\end{gathered}
$$

Diameter of idler gear is $75 \mathrm{~mm}$.

Permissible shear stresses:

$$
\begin{aligned}
& 0.30 S_{y t}=0.30 * 530=159 \mathrm{~N} / \mathrm{mm}^{2} \\
& 0.18 s_{u t}=0.18 * 800=144 \mathrm{~N} / \mathrm{mm}^{2}
\end{aligned}
$$

Lower of these two values are selected

i.e. $\tau=144 \frac{\mathrm{N}}{\mathrm{mm}^{2}}$

Since, keyways are present.

$$
\begin{array}{rl}
\therefore \tau_{\max }=0.75 & * 144 \\
& =108 \mathrm{~N} / \mathrm{mm}^{2} .
\end{array}
$$

According to ASME code and maximum shear stress theory of failure.

We have,

Maximum shear stress is given by,

$$
\tau_{\max }=\frac{16}{\pi * d^{3}} * \sqrt{\left(K_{b} * M_{b}\right)^{2}+\left(K_{t} * M_{t}\right)^{2}}
$$


Where,

$K_{b}=$ combined shock and fatigue factor applied to bending moment

$K_{t}=$ combined shock and fatigue factor applied to torsional moment

Torsional moment is given by,

$$
\begin{gathered}
M_{t}=P_{t} * \frac{d}{2} \\
=10793.6 * \frac{75}{2} \\
=404760 \mathrm{~N} \mathrm{~mm}
\end{gathered}
$$

For uniform load application,

$K_{b}=$ combined shock and fatigue factor applied to B.M $=1.5$

$K_{t}=$ combined shock and fatigue factor applied to T.M $=1$

According to ASME code and maximum shear stress theory of failure.

We have,

$$
\begin{aligned}
& \tau_{\text {max }}=\frac{16}{\pi * d^{3}} * \sqrt{\left(K_{b} * M_{b}\right)^{2}+\left(K_{t} * M_{t}\right)^{2}} \\
& d^{3}=\frac{16}{\pi * 10^{8}} * \sqrt{(1.5 * 335012.8)^{2}+(1 * 404760)^{2}} \\
& d^{3}=24777.15
\end{aligned}
$$

$\mathrm{d}=29.15 \mathrm{~mm}$.

The next standard diameter for shaft is

$\mathrm{d}=30 \mathrm{~mm}$

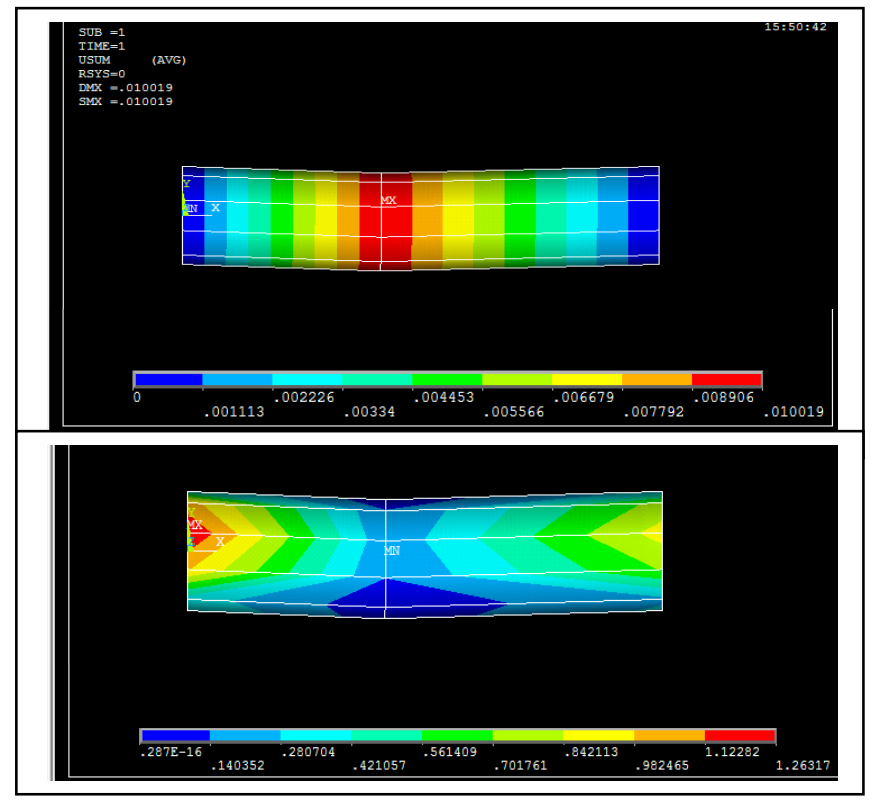

Figure 7 Stress analysis for idler shaft

\section{Design of Spindle Shaft}

Selection of material for shaft:

The shaft should have sufficient strength to resist failure due to breakage, provide rigidity and gives more stability. 
Considering above factors in mind the design experts from industries and design organization select the material for shaft as SAE8620.

$\mathrm{SAE} 8620 \rightarrow 20 N_{i} 2 C_{r} 1 M_{o} 15$

Composition $\rightarrow 0.20 \% \mathrm{C}, N_{i}-2 \%, C_{r}-1 \%, M_{o}-0.15 \%$

$s_{u t}=800 \mathrm{~N} / \mathrm{mm}^{2}$

$S_{y t}=530 \mathrm{~N} / \mathrm{mm}^{2}$

Diameter of idler gear is $75 \mathrm{~mm}$.

Permissible shear stresses:

$$
\begin{aligned}
& 0.30 S_{y t}=0.30 * 530=159 \mathrm{~N} / \mathrm{mm}^{2} \\
& 0.18 s_{u t}=0.18 * 800=144 \mathrm{~N} / \mathrm{mm}^{2}
\end{aligned}
$$

Lower of these two values are selected

i.e. $\tau=144 \frac{\mathrm{N}}{\mathrm{mm}^{2}}$

Since, keyways are present.

$$
\begin{aligned}
\therefore \tau_{\max } & =0.75 * 144 \\
& =108 \mathrm{~N} / \mathrm{mm}^{2} .
\end{aligned}
$$

According to ASME code and maximum shear stress theory of failure.

We have,

Maximum shear stress is given by,

$\tau_{\max }=\frac{16}{\pi * d^{3}} * \sqrt{\left(K_{b} * M_{b}\right)^{2}+\left(K_{t} * M_{t}\right)^{2}}$

Where,

$K_{b}=$ combined shock and fatigue factor applied to bending moment

$K_{t}=$ combined shock and fatigue factor applied to torsional moment

According to ASME code and maximum shear stress theory of failure.

We have,

$$
\begin{gathered}
\tau_{\text {max }}=\frac{16}{\pi * d^{3}} * \sqrt{\left(K_{b} * M_{b}\right)^{2}+\left(K_{t} * M_{t}\right)^{2}} \\
d^{3}=\frac{16}{\pi * 10^{8}} * \sqrt{(1.5 * 516882.3)^{2}+(1 * 356188.8)^{2}} \\
d^{3}=40235.6
\end{gathered}
$$

$\mathrm{d}=34.26 \mathrm{~mm}$.

The next standard diameter for shaft is

$\mathrm{d}=35 \mathrm{~mm}$

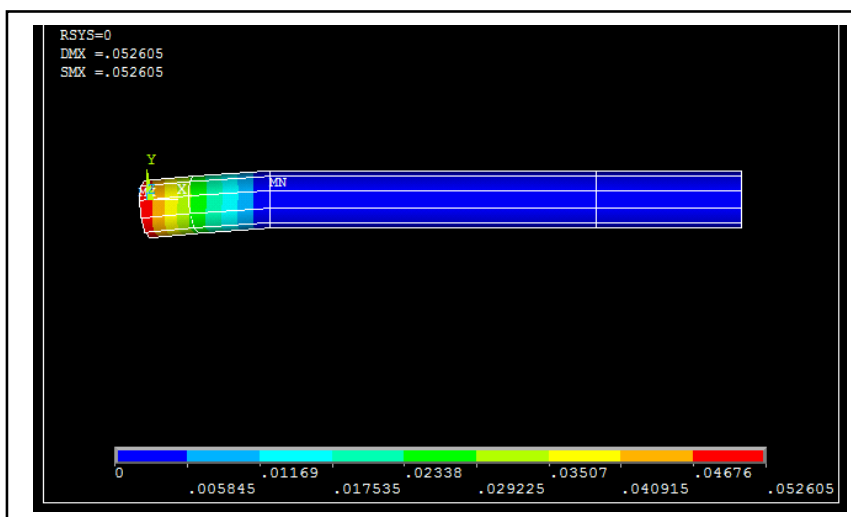




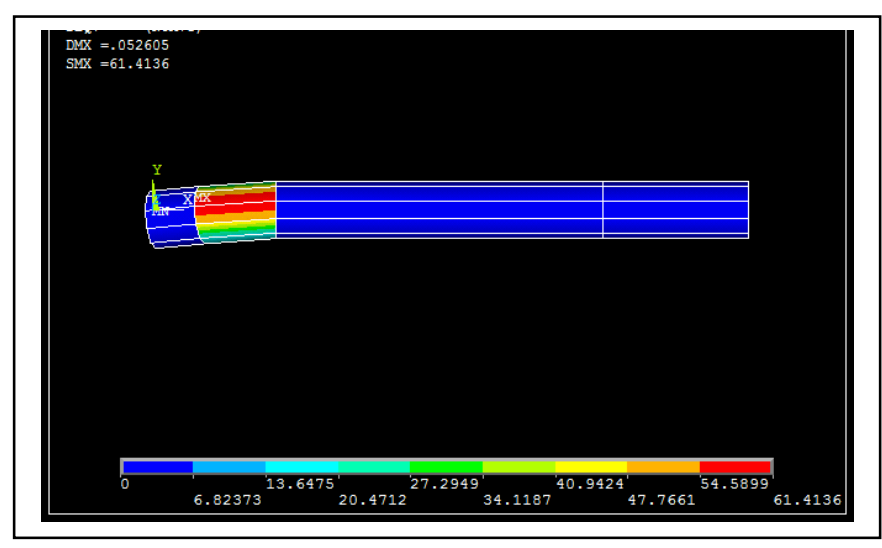

Figure 8 Stress analysis for spindle shaft

\section{Design of Intermediate Shaft}

Selection of material for shaft:

The shaft should have sufficient strength to resist failure due to breakage, provide rigidity and gives more stability.

Considering above factors in mind the design experts from industries and design organization select the material for shaft as SAE8620.

$$
\mathrm{SAE} 8620 \rightarrow 20 N_{i} 2 C_{r} 1 M_{o} 15
$$

Composition $\rightarrow 0.20 \% \mathrm{C}, N_{i}-2 \%, C_{r}-1 \%, M_{o}-0.15 \%$

$s_{u t}=800 \mathrm{~N} / \mathrm{mm}^{2}$

$S_{y t}=530 \mathrm{~N} / \mathrm{mm}^{2}$

Diameter of gear is $150 \mathrm{~mm}$.

Permissible shear stresses:

$$
\begin{aligned}
& 0.30 S_{y t}=0.30 * 530=159 \mathrm{~N} / \mathrm{mm}^{2} \\
& 0.18 s_{u t}=0.18 * 800=144 \mathrm{~N} / \mathrm{mm}^{2}
\end{aligned}
$$

Lower of these two values are selected

i.e. $\tau=144 \frac{\mathrm{N}}{\mathrm{mm}^{2}}$

Since, keyways are present.

$$
\begin{aligned}
\therefore \tau_{\text {max }} & =0.75 * 144 \\
& =108 \mathrm{~N} / \mathrm{mm}^{2} .
\end{aligned}
$$

According to ASME code and maximum shear stress theory of failure.

We have,

Maximum shear stress is given by,

$\tau_{\max }=\frac{16}{\pi * d^{3}} * \sqrt{\left(K_{b} * M_{b}\right)^{2}+\left(K_{t} * M_{t}\right)^{2}}$

Where,

$K_{b}=$ combined shock and fatigue factor applied to bending moment

$K_{t}=$ combined shock and fatigue factor applied to torsional moment

According to ASME code and maximum shear stress theory of failure.

We have, 


$$
\begin{gathered}
\tau_{\text {max }}=\frac{16}{\pi * d^{3}} * \sqrt{\left(K_{b} * M_{b}\right)^{2}+\left(K_{t} * M_{t}\right)^{2}} \\
d^{3}=\frac{16}{\pi * 10^{8}} * \sqrt{(1.5 * 804040.46)^{2}+(1 * 517716.2)^{2}} \\
d^{3}=61892.8
\end{gathered}
$$

$\mathrm{d}=39.55 \mathrm{~mm}$.

The next standard diameter for shaft is

$\mathrm{d}=45 \mathrm{~mm}$

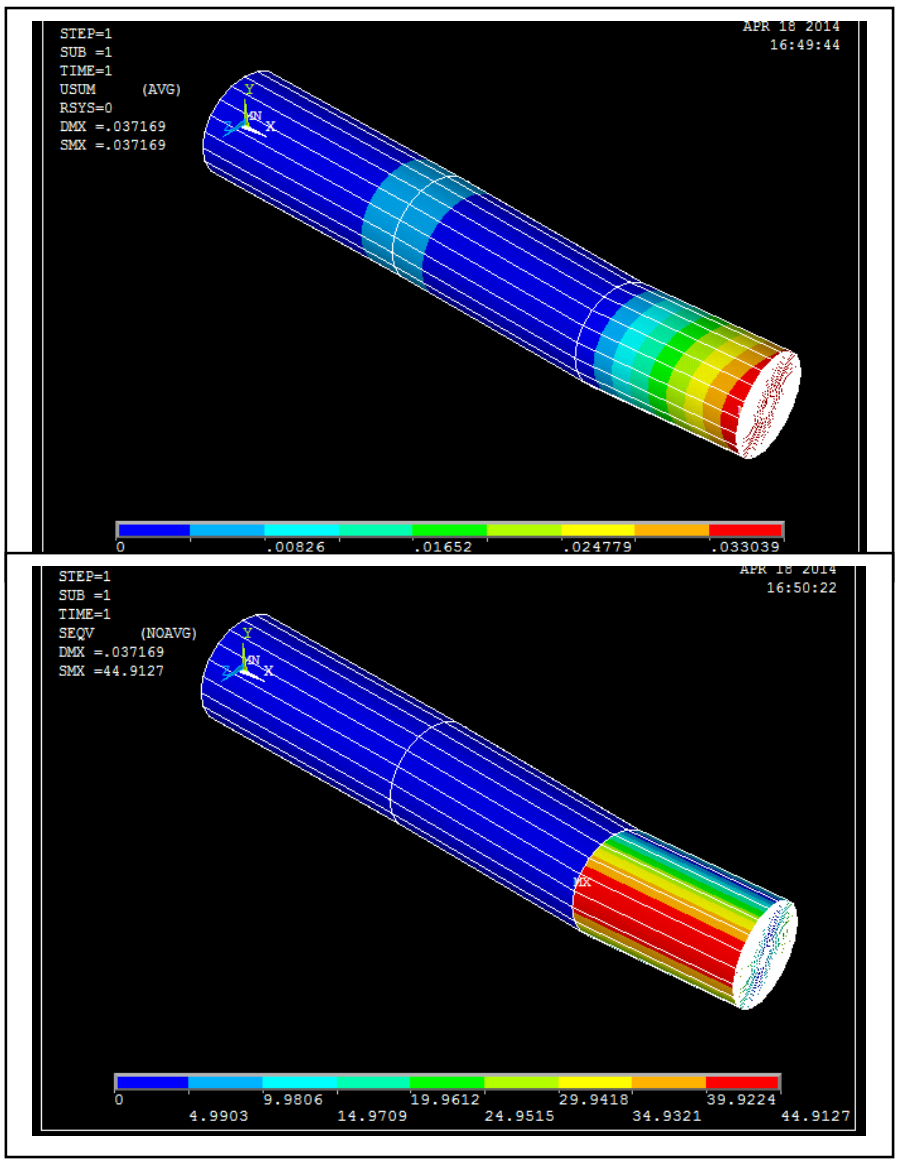

Figure 9 Stress analysis for intermediate shaft

\section{Design of Input Shaft}

Selection of material for shaft:

The shaft should have sufficient strength to resist failure due to breakage, provide rigidity and gives more stability.

Considering above factors in mind the design experts from industries and design organization select the material for shaft as SAE8620.

$$
\mathrm{SAE} 8620 \rightarrow 20 N_{i} 2 C_{r} 1 M_{o} 15
$$

Composition $\rightarrow 0.20 \% \mathrm{C}, N_{i}-2 \%, C_{r}-1 \%, M_{o}-0.15 \%$

$$
\begin{gathered}
s_{u t}=800 \mathrm{~N} / \mathrm{mm}^{2} \\
S_{y t}=530 \mathrm{~N} / \mathrm{mm}^{2}
\end{gathered}
$$

Diameter of gear is $150 \mathrm{~mm}$.

Permissible shear stresses: 


$$
\begin{aligned}
& 0.30 S_{y t}=0.30 * 530=159 \mathrm{~N} / \mathrm{mm}^{2} \\
& 0.18 s_{u t}=0.18 * 800=144 \mathrm{~N} / \mathrm{mm}^{2}
\end{aligned}
$$

Lower of these two values are selected

i.e. $\tau=144 \frac{\mathrm{N}}{\mathrm{mm}^{2}}$

Since, keyways are present.

$$
=108 \mathrm{~N} / \mathrm{mm}^{2} . \quad \therefore \tau_{\max }=0.75 * 144
$$

Torsional moment:-

$$
\begin{aligned}
M_{t} & =\frac{60 * 10^{6} * K w}{2 \pi n} \\
& =\frac{60 * 10^{6} * 14.92}{2 \pi * 430} \\
M_{t} & =331.338 * 10^{6} \mathrm{Nmm}
\end{aligned}
$$

Bending moment:

$P_{1}$ and $P_{2}$ are the belt tensions in tight and slack sides.

Now, $\left(P_{1}-P_{2}\right) * 150=331.338 * 10^{3}$

$$
\left(P_{1}-P_{2}\right)=2208.9
$$

Assume, $P_{1}=3 P_{2}$

From equation 1 and 2

$3 P_{2}-P_{2}=2208.9$

$\therefore P_{2}=1104.46 \mathrm{~N}$

$P_{1}=3313.38 N$

Now, $\left(P_{1}+P_{2}\right)=4417.84 \mathrm{~N}$

$P_{t}$ and $P_{r}$ are tangential and radial components of

$P_{t} * 48=331.338^{*} 10^{3}$

$P_{t}=6902.87 \mathrm{~N}$

Now, $P_{r}=P_{t} * \tan 20$

$P_{r}=6902.87 * \tan 20=2512.4 \mathrm{~N}$

According to ASME code and maximum shear stress theory of failure.

We have,

$\tau_{\max }=\frac{16}{\pi * d^{3}} * \sqrt{\left(K_{b} * M_{b}\right)^{2}+\left(K_{t} * M_{t}\right)^{2}}$

$d^{3}=\frac{16}{\pi * 108} * \sqrt{(1.5 * 662676)^{2}+(1 * 331338)^{2}}$

$d^{3}=49410.3$

$\mathrm{d}=36.7 \mathrm{~mm}$.

The next standard diameter for shaft is

$\mathrm{d}=40 \mathrm{~mm}$ 
Design of Multi Spindle Drilling Machine
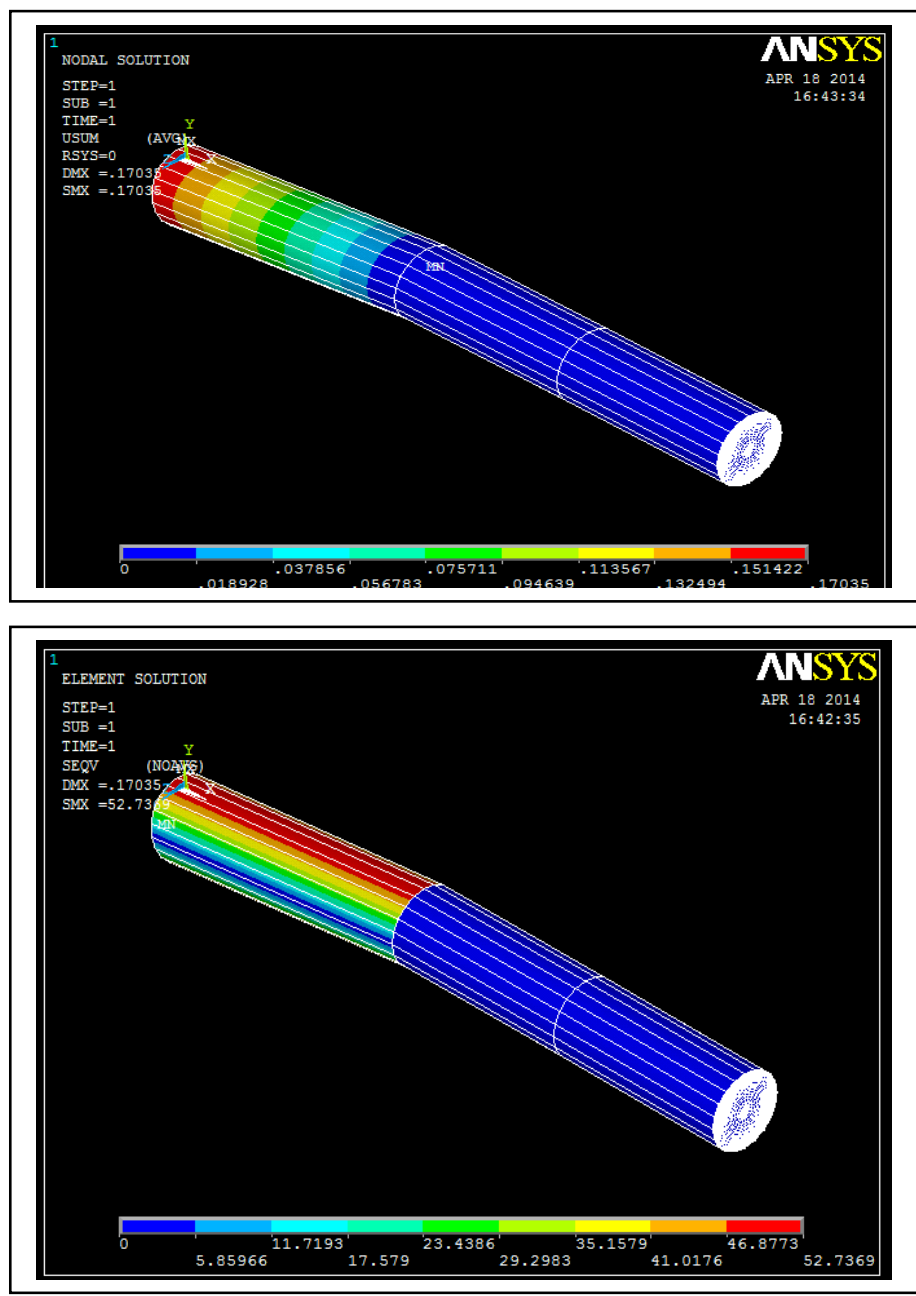

Figure 10 Stress analysis for intermediate shaft

\section{SELECTION OF BEARING}

For idler shaft:-

The bearing life for industrial application where the electric motor is used as prime motor and gear drive is in between 12000-20000 hours.

We select the lower value,

$\mathrm{L}_{10 \mathrm{~h}}=12000$ hour

Radial load,

Fr $=3928.5 \mathrm{~N}$

We know,

$$
\begin{aligned}
\mathrm{L}_{10} & =\frac{60 \times \mathrm{n} \times \mathrm{L}_{10 \mathrm{~h}}}{10^{6}} \\
& =\frac{60 \times 352 \times 12000}{10^{6}} \\
& =253.44 \mathrm{mrev}
\end{aligned}
$$

Equivalent radial load:-

$$
\mathrm{Fr}=\mathrm{P}=3928.5 \mathrm{~N}
$$

Dynamic load capacity,

$$
\begin{aligned}
& \mathrm{C}=\mathrm{P}\left(\mathrm{L}_{10}\right)^{1 / 3} \\
& \mathrm{C}=3928.5 \times(253.44)^{1 / 3}
\end{aligned}
$$


$\mathrm{C}=24860 \mathrm{~N}$

Thus, 6306 bearing no. is selected from table.

\begin{tabular}{|c|c|c|c|}
\hline Principal dia & \multicolumn{2}{|c|}{ Basic Load Rating } & Designation \\
\hline $\mathrm{d}_{\mathrm{B}} \mathrm{D}$ & $\mathrm{C}$ & $C_{0}$ & \\
\hline${ }^{30} 19{ }^{72}$ & 28100 & 14600 & 6306 \\
\hline
\end{tabular}

Similarly all shaft bearing selected through above procedure with their load carrying capacity.

\section{SUGGESTED ASSEMBLY PROCEDURE}

- Clean all parts like spindles, gears, plates, housing, shafts \& bearing

- Check all parts as per drawing.

- Firstly, setting down the machine bed at the assembly place.

- Assembly of the gear box housing.

- All bearings are mounted in the holes which are provided on the housing.

- All the bearings are lubricated by white grease.

○ Place spindle shafts where gears are mounted in the gear box housing.

- Place the spacers on each shaft.

- Fix the gear on the shafts with the help of keys.

- Place the star washer on each gear.

○ Tight the chuck nut to lock the gear.

○ Bend the protruding part of star washer in the space of chuck nut.

- All other idler shafts are placed at the prescribed locations.

- All idler gears are mounted on the shafts with the help of keys.

- Using the chuck nut and star washer idler gears are fixed to avoid lateral movements.

○ The main input gear is mounted on central shaft of housing.

- Second gear is mounted on same central shaft for purpose of speed reduction.

- The intermediate shaft is mounted on the two bearings provided in housing and cover plate of housing.

O On these intermediate shafts the gear and pulley are fixed.

- Mount the motor in upside down manner with the help of nut and bolt in such a way that the timing belt length can be adjusted to have sufficient tension.

- Mount the gear box housing assembly on the supports provided on the machine bed.

- The pulley and motor shaft are connected with the help of timing belt.

- Now, guide bars are mounted at the prescribed location(as per drawing) with the help of bolts, on the machine bed, on trail and error basis using jig plate.

- The bushes are pressed fitted at the four corners of the jig plate for sliding on guide bars.

- The jig plate are mounted on guide bars.

- Separate lubrication system is provided for each guide bar bush on jig plate. 
- Two top covers plates are provided on guide bars.

- All the drilling holes on jig plates are provided with bushes.

- Resting pads are provided on jig plate for resting the job.

- The damping cylinders are fitted on jig plate for each job.

- For movement of jig plate the hydraulic system consisting of two hydraulic cylinders are provided.

\section{LIMITATIONS}

- This Special Purpose Machine will be used only for one type of component.

- The initial investment is high.

- The cost of this machine affordable only when the production is in large quantity.

- Noise generation during drilling process.

High electricity required

\section{CONCLUSIONS}

The company used to manufacture around 14 jobs per shift using conventional drilling machine. But now with advent machine operation is carried out in the cycle time of 3 min to manufacture two pieces. By using advanced SPM, the company manufactures around 140 pieces per shift. This clearly reveals that the production rate will increase immensely. One operator, who looks the loading and unloading of the component, can simultaneously work on another machine .In this way, the lobour utilization of the company may improve and also add up to improve the economy involved in the total machining. This will justify the purpose of manufacturing this SPM machine.

\section{FUTURE SCOPE}

This machine can be improved in future by using different housing structures which can be accommodated on the machine bed making set up changes as per requirements of components with certain adjustments. Presently the SPM can drill the rear brake drum of heavy commercial vehicle and with different models for TELCO. This machine can also be used for their other model vehicles. Other models which differ by the centre distance between flanges can be accommodated provided the PCD remains same. In future to cover all components the part family flexibility can be achieved by replacing the drilling heads for components with different PCD. So by this arrangement SPM can be used for variety of components of same kind.

\section{REFERENCES}

[1] Machine tool design handbook, Central machine tool institute, Bangalore, 1st edition, reprint 2006

[2] R.S.Majumdar, Oil Hydraulic systems, Tata Mcgraw Hill Publication, Edition: - 2002

[3] K. Mahadevan and K. Balaveera Reddy, Design data hand book, - CBS publishers and distributers, third edition 1987.

[4] V.B.Bhandari ,Design of machine elements, Tata McGraw hill, 2007 Edition

[5] Dr. U. Sathish Rao and Dr. Lewlyn L.R. Rodrigues. Enhancing the Machining Performance of HSS Drill in the Drilling of GFRP Composite by Reducing Tool Wear through Wear Mechanism. International Journal of Mechanical Engineering and Technology, 8(1), 2017, pp. 120-131. 
[6] Syed Mohibuddin Bukhari and M. Manzoor Hussain, Greener, Evaluation of Optimum Process Parameters in Drilling Process of Hybrid Composites using Taguchi Method. International Journal of Mechanical Engineering and Technology, 8(4), 2017, pp. 194201.

[7] Vikas Mukhraiya, Raj Kumar Yadav and Pooja Tiwari, Optimization of Drilling Parameters Using Grey Based Taguchi Method. International Journal of Advanced Research in Engineering and Technology, 6(12), 2015, pp. 16-24 